\title{
Characterization of a glycerol kinase mutant of Aspergillus niger
}

\author{
Cor F. B. Witteveen, ${ }^{1}$ Peter van de Vondervoort,${ }^{1}$ Cor Dijkema, ${ }^{2}$ KlaAs Swart ${ }^{1}$ and \\ JAAP VISSER ${ }^{1 *}$
}

Departments of ${ }^{1}$ Genetics and ${ }^{2}$ Molecular Physics, Agricultural University, Dreyenlaan 2, 6703 HA Wageningen, The Netherlands

(Received 18 December 1989; accepted 16 March 1990)

\begin{abstract}
A glycerol-kinase-deficient mutant of $A$ spergillus niger was isolated. Genetic analysis revealed that the mutation is located on linkage group VI. The phenotype of this mutant differed from that of a glycerol kinase mutant of Aspergillus nidulans in its ability to utilize dihydroxyacetone (DHA). The weak growth on glycerol of the $A$. niger glycerol kinase mutant showed that glycerol phosphorylation is an important step in glycerol catabolism. The mutant could still grow normally on DHA because of the presence of a DHA kinase. This enzyme, probably in combination with an $\mathrm{NAD}^{+}$-dependent glycerol dehydrogenase, present only in the mutant, is responsible for the weak growth of the mutant on glycerol. Enzymic analysis of both the mutant and the parental strain showed that at least three different glycerol dehydrogenases were formed under different physiological conditions: the NAD ${ }^{+}$dependent enzyme described above, a constitutive NADP+ ${ }^{+}$-dependent enzyme and a D-glyceraldehyde-specific enzyme induced on D-galacturonate. The glycerol kinase mutant showed impaired growth on D-galacturonate.
\end{abstract}

\section{Introduction}

Glycerol plays a central role in the physiology of many organisms. Its role in the regulation of the osmotic potential of cells is generally recognized (Brown, 1976, 1978). The function of glycerol as an osmoticum has also been demonstrated in filamentous fungi (Hocking \& Norton, 1983; Beever \& Laracy, 1986). Furthermore, glycerol is involved in metabolic processes occurring during germination of fungal spores (Van Laere \& Hulsmans, 1987) and is also an intermediate in the breakdown of some compounds, for example galacturonic acid (Uitzetter et al., 1986). Glycerol formation plays a role during citric acid production by Aspergillus niger (Röhr et al., 1987). Legisa \& Mattey (1986) suggested that glycerol accumulation initiates this process.

The catabolic pathways of glycerol utilization have been investigated in many organisms (Lin, 1976, 1977). These studies demonstrated that there are two alternative pathways. In one, the phosphorylating pathway, glycerol is phosphorylated and subsequently oxidized to dihydroxyacetone phosphate (DHAP) by a flavindependent membrane-bound mitochondrial glycerol-3phosphate dehydrogenase (Gancedo et al., 1968). In the

Abbreviations: DHA, dihydroxyacetone; DHAP, dihydroxyacetone phosphate; GAD, D-glyceraldehyde; MTT, 3-(4,5-dimethylthiazolyl2)-2,5-diphenyl tetrazolium bromide; PMS, phenazine methosulphate. other, the oxidation pathway, glycerol is oxidized to dihydroxyacetone (DHA) followed by phosphorylation to DHAP (May \& Sloan, 1981; May et al., 1982; Gancedo et al., 1986). The first pathway is used by most organisms.

In the filamentous fungus Neurospora crassa glycerol is catabolized through the phosphorylating pathway (Courtright, 1975 $a, b ;$ Holm et al., 1976). Three classes of glycerol non-utilizing mutants have been isolated in Aspergillus nidulans: glcA, glcB (Payton, 1978; Uitzetter et al., 1986) and glcC (Visser et al., 1988). glcA and glcB are deficient in glycerol kinase and FAD-dependent glycerol-3-phosphate dehydrogenase respectively ( $\mathrm{J}$. Visser and co-workers, unpublished results), and $g l c C$ is a glycerol uptake mutant. This demonstrates that $A$. nidulans also uses the phosphorylating pathway.

There were three reasons for us to investigate glycerol metabolism in $A$. niger: (1) glycerol metabolism appears to be different from that in $A$. nidulans and $N$. crassa; (2) it has an important role in osmotic regulation; and (3) it may be involved in citric acid production in $A$. niger.

\section{Methods}

Biochemicals. DHAP, D-glyceraldehyde (GAD) and 3-(4,5-dimethylthiazolyl-2)-2,5-diphenyl tetrazolium bromide (MTT) were from Sigma. NAD(P)+, NAD(P)H, ATP, glycerol 3-phosphate and glycerol3-phosphate dehydrogenase were supplied by Boehringer Mannheim. 
Phenazine methosulphate (PMS) and dihydroxyacetone (DHA) were from Serva. Other chemicals were from Merck. Sephadex G-25 and the Mono-Q column were obtained from Pharmacia.

Isolation of the mutant and genetic mapping of the mutation. The parental strain used in this investigation was the auxotrophic and morphological mutant N423, derived from $A$. niger N400 (CBS 120-49). The markers of this mutant are short conidiophores (cspAI) and nicotinamide deficiency (nicAl) (Bos et al., 1988).

Mutations were induced by UV treatment. A suspension of conidia $\left(8 \times 10^{6} \mathrm{ml}^{-1}\right)$ in a Petri dish was irradiated for $2.5 \mathrm{~min}$ with $2 \mu \mathrm{J} \mathrm{mm}^{-2} \mathrm{~s}^{-1}$ resulting in $70 \%$ survival (Bos, 1987). A filtration enrichment procedure was used as described essentially by Uitzetter $e t$ al. (1986). A sample $(10 \mathrm{ml})$ of the irradiated conidia and $40 \mathrm{ml}$ minimal medium, with D-galacturonate as carbon source, were used. The conidial suspension was incubated at $30^{\circ} \mathrm{C}$ in a rotary shaker. The medium was filtered twice and renewed once a day. The enrichment procedure was continued for $10 \mathrm{~d}$ after which time $1.3 \times 10^{6}$ conidia were left. The conidia were rescued on complete medium with glucose as carbon source and grown for $48 \mathrm{~h}$ at $30^{\circ} \mathrm{C}$. The colonies obtained were tested on minimal medium with glucose, acetate or Dgalacturonate as carbon source. Mutants which showed defective growth on D-galacturonate were selected for further analyses.

The linkage group of the mutation was determined by somatic recombination with a tester strain (N655) carrying a colour marker and auxotrophic markers on different linkage groups, i.e. fwnAl (I), hisD4 (II), lysA7, bioAl (III), leuAl (IV), metBl (V) and pabAl (VI). The origin and characterization of this strain were described by Bos et al. (1988). Isolation of diploids and haploidization was done according to Bos et al. (1988). Segregants were analysed for genetic markers and the linkage of the mutation with the markers of the tester strain was determined.

Media and growth conditions. Minimal medium contained $\left(1^{-1}\right): 1.5 \mathrm{~g}$ $\mathrm{KH}_{2} \mathrm{PO}_{4}, 0.5 \mathrm{~g} \mathrm{KCl}, 0.5 \mathrm{~g} \mathrm{MgSO}_{4} .7 \mathrm{H}_{2} \mathrm{O}, 6 \mathrm{~g} \mathrm{NaNO}_{3}, 0.1 \mathrm{~g}$ yeast extract, $0.9 \mathrm{mg} \quad \mathrm{ZnSO}_{4} .7 \mathrm{H}_{2} \mathrm{O}, 0.2 \mathrm{mg} \quad \mathrm{MnCl}_{2} .4 \mathrm{H}_{2} \mathrm{O}, 0.06 \mathrm{mg}$ $\mathrm{CoCl}_{2} .6 \mathrm{H}_{2} \mathrm{O}, 0.06 \mathrm{mg} \mathrm{CuSO}{ }_{4} .5 \mathrm{H}_{2} \mathrm{O}, 0.04 \mathrm{mg}\left(\mathrm{NH}_{4}\right)_{6} \mathrm{Mo}_{7} \mathrm{O}_{24} .4 \mathrm{H}_{2} \mathrm{O}$, $0.29 \mathrm{mg} \mathrm{CaCl} \cdot 2 \mathrm{H}_{2} \mathrm{O}$ and $0.2 \mathrm{mg} \mathrm{FeSO} \mathrm{F}_{4} \cdot 7 \mathrm{H}_{2} \mathrm{O}$. In all experiments minimal medium was supplemented with $1 \mathrm{mg}$ nicotinamide $\mathrm{l}^{-1}$. The carbon source was $100 \mathrm{~mm}$-glucose, DHA or glycerol or $50 \mathrm{~mm}$ galacturonate; these were added separately as membrane-filtersterilized solutions. The growth temperature for all experiments was $30^{\circ} \mathrm{C}$.

Conidiospores were harvested from cultures on complete medium according to Pontecorvo et al. (1953) except that glucose was replaced by $2 \%(\mathrm{w} / \mathrm{v})$ sucrose. Mycelium was grown in 1 litre Erlenmeyer flasks containing $300 \mathrm{ml}$ of medium, inoculated with approximately $10^{6}$ conidiospores $\mathrm{ml}^{-1}$ and incubated in a New Brunswick rotary shaker for $20-24 \mathrm{~h}$ at 280 r.p.m.

To measure enzyme activities induced by glycerol or galacturonate in the $A$. niger mutant NW201, mycelium grown on glucose for $24 \mathrm{~h}$ was transferred for $16 \mathrm{~h}$ to minimal medium containing either of these substrates. Growth tests were done on Petri dishes containing minimal medium, $1 \cdot 2 \%(\mathrm{w} / \mathrm{v})$ agar and $50 \mathrm{~mm}$ of one of the carbon sources.

Preparation of mycelium and mycelial extracts for NMR measurements. Mycelia of the parental strain N423 and the glycerol mutant NW201, grown for $24 \mathrm{~h}$ in minimal medium with $2 \%(\mathrm{w} / \mathrm{v})$ sucrose and subsequently transferred for $16 \mathrm{~h}$ to minimal medium containing either DHA or D-galacturonate as carbon source, were harvested and prepared for NMR measurements as described by Dijkema et al. (1985). Mycelia of the mutant and the parental strain grown on sucrose $(2 \%, w / v)$ for $24 \mathrm{~h}$ and transferred for $16 \mathrm{~h}$ to glycerol were harvested by filtration, washed with distilled water and frozen in liquid nitrogen. The frozen mycelium was extracted with $10 \%(\mathrm{v} / \mathrm{v}) \mathrm{HClO}_{4}$ as follows:
$1.5 \mathrm{~g}$ (wet wt) frozen mycelium was crushed in a mortar and added in small portions to $3 \mathrm{ml}$ ice-cold $10 \% \mathrm{HClO}_{4}$ in a Potter-Elvejhem homogenizer and homogenized. This suspension was frozen in liquid nitrogen, allowed to thaw and vortexed. The freeze-thaw procedure was repeated twice to allow quantitative liberation of the cell metabolites (Weibel et al., 1974). This extract was centifuged in the cold for $10 \mathrm{~min}$ at $10000 \mathrm{~g}$. The supernatant was neutralized with $\mathrm{KHCO}_{3}$ after which the precipitate was removed by centrifugation. The supernatant was used for NMR measurements.

NMR measurements. ${ }^{13} \mathrm{C}$ NMR spectra of mycelia and mycelial extracts were obtained at $75.46 \mathrm{MHz}$ on a Bruker CXP-300 NMR spectrometer using $10 \mathrm{~mm}$ NMR tubes. Mycelial spectra were acquired by accumulation of 7200 transients with a $60^{\circ}$ flip angle and $0.5 \mathrm{~s}$ recycle time $(1 \mathrm{~h})$, applying broadband proton noise decoupling. Spectra of mycelial extracts were acquired by accumulating 3600 transients with a $30^{\circ}$ flip angle and $1 \mathrm{~s}$ recycle time $(1 \mathrm{~h})$, using the standard composition Waltz pulse sequence for proton decoupling. In all cases the measuring temperature was kept close to $0^{\circ} \mathrm{C}$.

Preparation of cell-free extracts. Mycelium was harvested by filtration, washed with $0.85 \% \mathrm{NaCl}$ and frozen in liquid nitrogen. The frozen mycelium was disrupted in a Braun homogenizer and subsequently suspended in extraction buffer $(50 \mathrm{mM}-\mathrm{Tris} / \mathrm{HCl}, \mathrm{pH} 8.0$, $5 \mathrm{mM}-\mathrm{MgCl}_{2}$ ). After $1 \mathrm{~h}$ the homogenate was centrifuged at $1000 \mathrm{~g}$ for $30 \mathrm{~s}$ to remove cell debris. The supernatant was centrifuged at $10000 \mathrm{~g}$ for $10 \mathrm{~min}$. The pellet from this high-speed centrifugation was resuspended in extraction buffer and used for the measurement of FAD-dependent glycerol-3-phosphate dehydrogenase (EC 1.1.99.5). The supernatant was used for the other enzyme measurements.

Fractionation of cell-free extract. Cell-free extract $(1 \mathrm{ml})$ was fractionated on a FPLC Mono-Q column using a $0-0.5 \mathrm{M}-\mathrm{NaCl}$ gradient in $20 \mathrm{~mm}$-Tris/ $\mathrm{HCl}, \mathrm{pH} 7.5,5 \mathrm{~mm}-\mathrm{MgCl}_{2}, 1 \mathrm{~mm}-\beta$-mercaptoethanol. Fractions of $0.4 \mathrm{ml}$ were collected and DHA kinase and GAD kinase were measured as described below.

Enzyme assays. Enzyme activities were measured at $25^{\circ} \mathrm{C}$ using an Aminco DW-2 spectrophotometer in the dual wavelength mode, measuring $A_{340}-A_{380}$. A value of $5.33 \mathrm{~mm}^{-1} \mathrm{~cm}^{-1}$ was used for the absorption coefficient of NAD(P)H. The enzyme assays were done in a $1 \mathrm{ml}$ volume. DHA kinase (EC 2.7.1.28) was measured in a mixture containing: $50 \mathrm{~mm}$-Tris/HCl, pH 8.0, $5 \mathrm{~mm}-\mathrm{MgCl}_{2}, 5 \mathrm{~mm}-\mathrm{ATP}$, 0.2 mM-NADH, 3 units of glycerol-3-phosphate dehydrogenase, 30 units of triosephosphate isomerase and $10 \mathrm{~mm}$-DHA. GAD kinase was determined by the same method as DHA kinase except that $10 \mathrm{mM}^{-}$ GAD was used. FAD-independent membrane-bound glycerol-3phosphate dehydrogenase (EC 1.1.99.5) was measured in the resuspended pellet from the high-speed centrifugation step (see above) using a modification of the method of Adler et al. (1985). The reaction mixture contained: $50 \mathrm{mM}-\mathrm{HEPES} / \mathrm{NaOH}, \mathrm{pH} 7.5,10 \mathrm{~mm}-\mathrm{KCN}$, 0.5 mM-MTT, 0.2 mM-PMS, 0.05\% Triton X-100 and 10 mM-L-glycerol3-phosphate. An absorption coefficient for reduced MTT at $550 \mathrm{~nm}$ of $8 \cdot 1 \mathrm{~mm}^{-1} \mathrm{~cm}^{-1}$ was used. Glycerol dehydrogenase (EC 1.1.1.6) was measured in a mixture containing $100 \mathrm{~mm}$-glycine $/ \mathrm{NaOH}$ buffer, pH 9.6, 0.4 mM-NAD(P)+ and $100 \mathrm{~mm}$-glycerol. DHA reductase and GAD reductase were measured in a mixture containing $50 \mathrm{~mm}$-sodium phosphate buffer, $\mathrm{pH} 6.5,0.2 \mathrm{~mm}-\mathrm{NAD}(\mathrm{P}) \mathrm{H}$ and $10 \mathrm{~mm}-\mathrm{DHA}$ or -GAD. Glycerol kinase (EC 2.7.1.30) was assayed by the discontinuous assay described by de Koning et al. (1987).

Analytical methods. Protein concentration was estimated, after denaturation and precipitation of protein with sodium deoxycholate and trichloroacetic acid (Bensadoun \& Weinstein, 1976), by the microbiuret method (Itzhaki \& Gill, 1964) using BSA as standard. 


\section{Results}

\section{Isolation of the mutant and genetic mapping of the mutation}

After the filtration enrichment $1.3 \times 10^{6}$ conidiospores were left from which 1200 colonies were rescued. Screening of these colonies revealed only one (NW201) that was unable to grow on galacturonate. The mutation in this glycerol-negative mutant was denoted glcAl.

Upon haploidization of a diploid obtained from a heterokaryon of NW201 and the tester strain N655, 105 segregants were analysed. The frequency of recombination between glcAl and pabAl was $8.6 \%$, whereas the recombination frequency with all the other markers varied between $44 \%$ and $53 \%$. Therefore the glcAl mutation is located on linkage group VI. The recombination between markers known to be located in one linkage group was $1.9 \%$ for nicAI and metBl (linkage group V).

\section{Growth characteristics}

Growth of the mutant NW201 and the parental strain N423 was tested on agar plates for a number of carbon sources. Growth on glucose, acetate and gluconate was the same in both the mutant and the parental strain. The mutant grew only slightly slower on DHA. A greater effect of the mutation was seen on glycerol or $D^{-}$ galacturonate, since with these carbon sources only weak growth was observed in the mutant compared to the parental strain. In addition, we observed a decreased ability of the glycerol-negative mutant to sporulate.
Enzyme activities in the wild-type and in mutant NW201

Table 1 summarizes the enzyme activities related to glycerol metabolism in cell-free extracts from the wildtype and from the mutant. All the activities were measured at least twice and the mean of these values is given. The reproducibility was reasonable, activities from different mycelia not varying more than $10-20 \%$. The results show that glycerol kinase activity could not be measured in any of the mycelial extracts of mutant NW201, while the other enzymes were present. It was thus concluded that the glcAl mutation causes a glycerol kinase deficiency.

The other enzyme activities showed no significant differences between the mutant and the parental strain when grown on glucose. The other three substrates, however, seemed to cause greater induction of a number of activities in the mutant: DHA kinase, GAD kinase, FAD-dependent glycerol-3-phosphate dehydrogenase and a $\mathrm{NAD}^{+}$-dependent glycerol dehydrogenase. The latter activity is very low in the parental strain and seems to be relatively specific for DHA since the activity of the NADH-dependent DHA reductase is increased in the same mycelial extracts whereas the NADH-dependent GAD reductase activity is much lower.

Apart from the $\mathrm{NAD}^{+}$-dependent glycerol dehydrogenase there are at least two other glycerol dehydrogenases, both $\mathrm{NADP}^{+}$-dependent. One is induced on $\mathrm{D}^{-}$ galacturonate and is relatively specific for GAD. The other is found especially in glucose-grown mycelium and is slightly repressed by the other three substrates. This repressive effect is even stronger in the mutant. This

Table 1. Enzyme activities involved in glycerol metabolism in the A. niger glycerol kinase mutant NW201 and the parental strain $N 423$

Mycelia were grown for 20-24 h on the carbon source indicated, except in the case of the mutant NW201 on glycerol and D-galacturenate, for which mycelium was grown for $24 \mathrm{~h}$ on minimal medium with glucose and subsequently transferred for $16 \mathrm{~h}$ to minimal medium with either glycerol or D-galacturonate.

\begin{tabular}{|c|c|c|c|c|c|c|c|c|}
\hline \multirow[b]{3}{*}{ Enzyme } & \multicolumn{8}{|c|}{ Enzyme activity [nmol $\left.\mathrm{min}^{-1}(\mathrm{mg} \text { protein })^{-1}\right]$} \\
\hline & \multicolumn{4}{|c|}{ A. niger NW201 grown on: } & \multicolumn{4}{|c|}{ A. niger N423 grown on: } \\
\hline & Glucose & DHA & $\begin{array}{l}\text { (transfer to) } \\
\text { Glycerol }\end{array}$ & $\begin{array}{c}\text { (transfer to) } \\
\text { D-Galacturonate }\end{array}$ & Glucose & DHA & Glycerol & D-Galacturonate \\
\hline DHAP reductase & 19 & 15 & 14 & 10 & 12 & 8 & 10 & 27 \\
\hline DHAP kinase & 0 & 208 & 290 & 688 & 4 & 46 & 21 & 29 \\
\hline D-Glyceraldehyde kinase & 0 & 136 & 195 & 426 & 0 & 30 & 10 & 12 \\
\hline Glycerol-3-phosphate dehydrogenase & 3 & 55 & 95 & 289 & 5 & 18 & 6 & 13 \\
\hline Glycerol dehydrogenase (NADP ${ }^{+}$) & 145 & 19 & 56 & 189 & 111 & 83 & 60 & 98 \\
\hline Glycerol dehydrogenase $\left(\mathrm{NAD}^{+}\right)$ & 0 & 6 & 25 & 62 & 0 & 5 & 0 & 0 \\
\hline DHA reductase (NADPH) & 925 & 70 & 238 & 276 & 623 & 353 & 362 & 535 \\
\hline DHA reductase (NADH) & 0 & 64 & 252 & 212 & 0 & 8 & 0 & 3 \\
\hline GAD reductase (NADPH) & 625 & 138 & 277 & 1534 & 537 & 403 & 327 & 1283 \\
\hline GAD reductase (NADH) & 0 & 35 & 74 & 110 & 14 & 38 & 5 & 15 \\
\hline Glycerol kinase & 0 & 0 & 0 & 0 & 9 & 77 & 40 & 35 \\
\hline
\end{tabular}




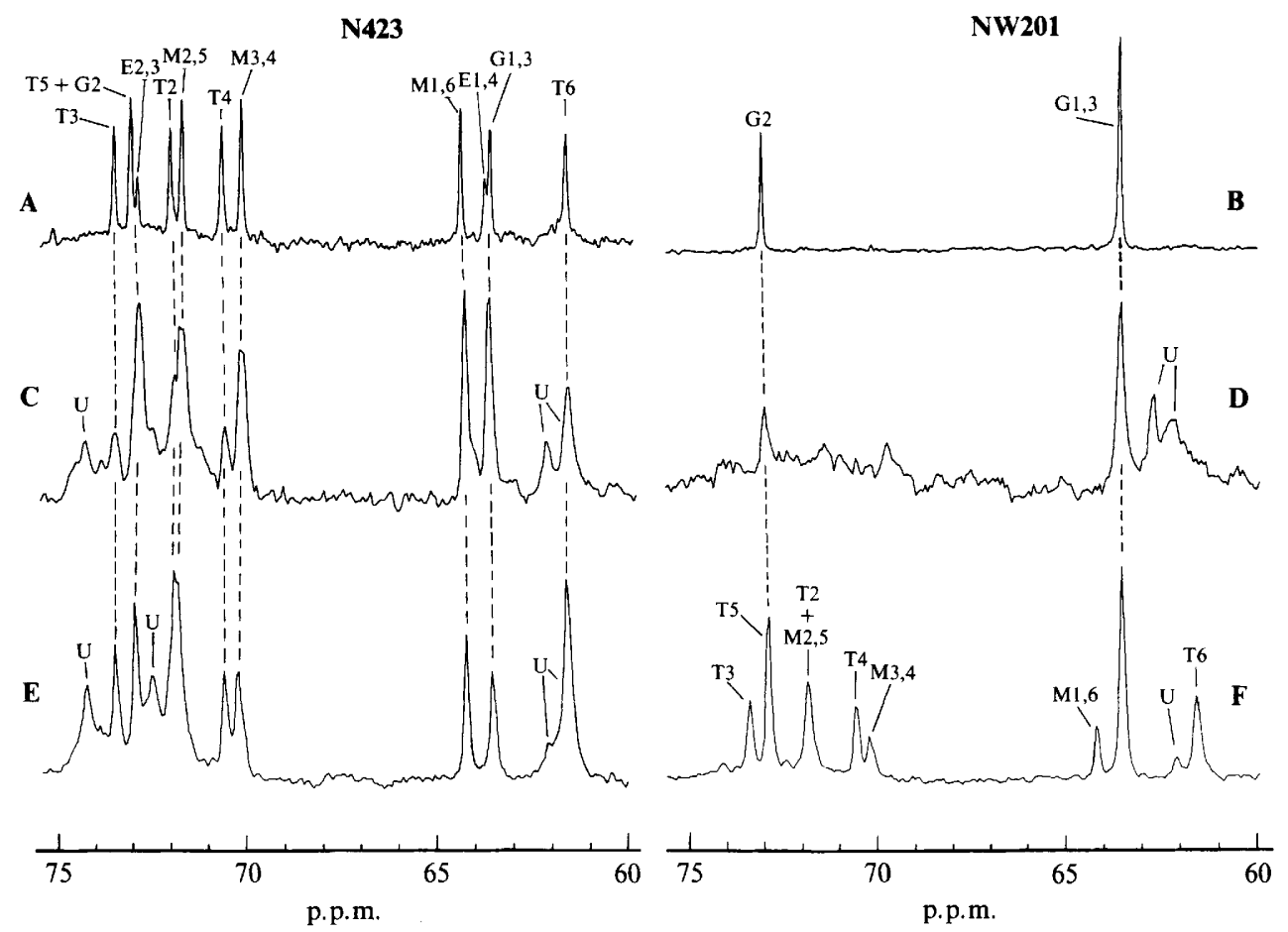

Fig. $1 .{ }^{13} \mathrm{C}$ NMR spectra of extracts of mycelia (A, B) and of mycelia (C, D, E, F) of the $A$. niger parental strain N423 (A, C, E) and the glycerol kinase mutant NW201 (B, D, F). Spectra were determined $16 \mathrm{~h}$ after transfer of mycelia to glycerol (A, B), D-galacturonate (C, D) or DHA (E, F). Details are given in Methods. M, mannitol; E, erythritol; G, glycerol; T, trehalose; U, unidentified resonance.

enzyme is relatively specific for DHA and is probably the same enzyme as the one partly purified by Baliga et al. (1962). It has been purified and characterized in our laboratory (Schuurink et al., 1990) and is relatively specific for DHA, GAD giving only $10 \%$ of the DHA reductase activity.

\section{Metabolite accumulation in the wild-type and in mutant NW201}

Mycelia of N423 and NW201, grown for $24 \mathrm{~h}$ on sucrose, were transferred for $16 \mathrm{~h}$ to minimal medium with DHA, D-galacturonate or glycerol as carbon source. ${ }^{13} \mathrm{C}$ NMR spectra of mycelia transferred to DHA and D-galacturonate or of extracts of mycelia after transfer to glycerol are shown in Fig. 1. The spectra of the mycelia of the wildtype and the mutant grown on sucrose for $24 \mathrm{~h}$ were essentially the same as those shown by Witteveen $e t a l$. (1989), that is high levels of mannitol and to a lesser extent of erythritol were accumulated. After transfer to glycerol, D-galacturonate or DHA, the parental strain accumulated glycerol and mannitol and the disaccharide trehalose (Fig. 1A, C, E). These metabolites are usually seen in mycelium grown on substrates whose metabolism is associated with glycerol, as in $A$. nidulans (Dijkema $e t$ al., 1985). The period of $16 \mathrm{~h}$ was long enough for the mycelium to adapt to the new carbon sources and to grow on them. The mutant mycelia transferred to glycerol or Dgalacturonate accumulated only glycerol (Fig. 1B, D). These results demonstrate that $\mathrm{D}$-galacturonic acid is converted to glycerol, which cannot be further metabolized by the mutant, and also that the mutant can take up glycerol. The mannitol and erythritol pools were depleted by the mutant under these conditions, since no other substrates were available. Transfer of the mutant to DHA (Fig. 1F) gave high levels of glycerol, trehalose and mannitol, although lower than those observed on the transfer of the parental strain to DHA (Fig. 1E). Thus DHA can still be metabolized by the mutant.

\section{DHA kinase and GAD kinase}

The results in Table 1 suggest that phosphorylation of DHA and of GAD are catalysed by a single enzyme. Since it was of importance for interpretation of the induction characteristics to test this further, we fractionated an extract of the mutant mycelium, grown for $24 \mathrm{~h}$ on sucrose and subsequently transferred to D-galacturonate for $16 \mathrm{~h}$, on an FPLC Mono-Q column. All the fractions were tested for DHA and GAD kinase 


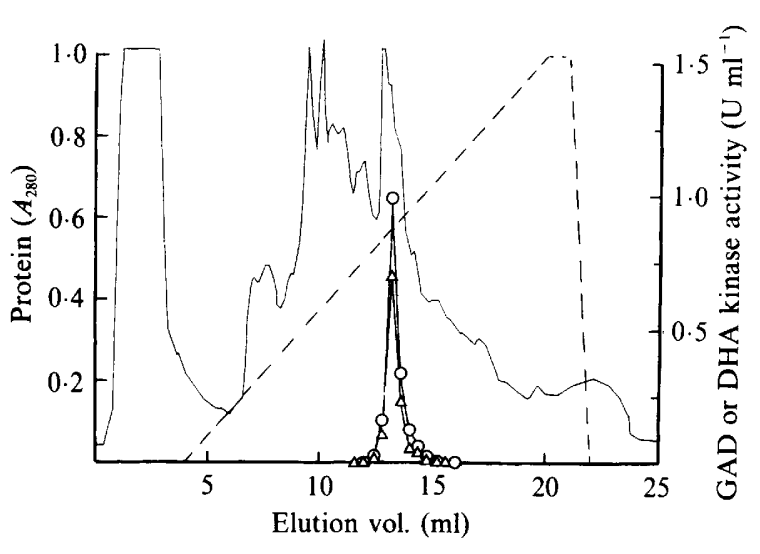

Fig. 2. Fractionation of cell-free extract of mycelium of the glycerol kinase mutant NW201. The mutant was grown for $24 \mathrm{~h}$ on glucose and subsequently transferred for $15 \mathrm{~h}$ to minimal medium with Dgalacturonate. An FPLC Mono-Q column was used. Elution was with a gradient (---) of $0-0.5 \mathrm{M}-\mathrm{NaCl}$ in $20 \mathrm{~mm}-\mathrm{Tris} / \mathrm{HCl}, \mathrm{pH} 7.5$; fractions of $0.4 \mathrm{ml}$ were collected. Protein eluting from the column was determined as the $A_{280}(-)$. DHA kinase $(O)$ and GAD kinase $(\triangle)$ activities were measured in all fractions; only the levels in fractions containing detectable kinase activities are indicated.

activities. The two activities eluted simultaneously (Fig. 2), a strong indication that both are catalysed by the same enzyme. Only those fractions showing some phosphorylating activity are shown in Fig. 2. These partly purified preparations were also used for some preliminary kinetic measurements. By varying the DHA or GAD concentrations we found that the concentration required to obtain half of the maximum velocity was approximately 5$10 \mu \mathrm{M}$ for DHA and 30-100 $\mu \mathrm{M}$ for GAD.

\section{Discussion}

The phenotype of the glycerol kinase mutant demonstrates that glycerol catabolism in $\boldsymbol{A}$. niger occurs by the phosphorylation of glycerol to glycerol 3-phosphate and subsequent oxidation by an FAD-dependent glycerol-3phosphate dehydrogenase, the same pathway as used by Neurospora crassa (Courtright, $1975 a, b$ ) and $A$. nidulans (unpublished results from our laboratory).

The fact that the glycerol kinase mutant grows only weakly on glycerol, even though glycerol dehydrogenase and DHA kinase are present, can be explained by the very unfavourable equilibrium for oxidation of glycerol to DHA (McGregor et al., 1974). It is remarkable, though, that in the glycerol kinase mutant, where the phosphorylation route is blocked, an $\mathrm{NAD}^{+}$-dependent glycerol dehydrogenase is induced. We postulate this enzyme to be responsible for the weak growth which is still observed on glycerol. Organisms which catabolize glycerol via the oxidation of glycerol also use an $\mathrm{NAD}^{+}$. dependent glycerol dehydrogenase (Lin, 1976; May \& Sloan, 1981). The lower catabolic reduction charge in the cell compared to the anabolic reduction charge favours the $\mathrm{NAD}^{+}$-dependent oxidation of glycerol. From this point of view the results of St Martin et al. (1975) are of interest. From an E. coli parental strain with defects both in the glycerol kinase and in the FAD-dependent glycerol-3-phosphate dehydrogenase genes, and thus unable to grow on glycerol, a mutant was selected which could utilize glycerol. This mutant overproduced an $\mathrm{NAD}^{+}$-dependent glycerol dehydrogenase, enabling the utilization of glycerol via the oxidative route.

The ability of the glycerol kinase mutant to grow on DHA and the presence of DHA kinase is an indication that the major degradation pathway for DHA in wildtype mycelium is by direct phosphorylation and not via reduction to glycerol. This, however, may be an oversimplification. In mutant mycelium grown on DHA the level of DHA reductase is strongly repressed while the level of DHA kinase is much higher than in the parental strain. Furthermore, the NMR spectra of the mycelia grown on DHA show a different metabolite accumulation pattern in the mutant as compared to the parental strain grown on DHA. Therefore, it may be that in the parental strain DHA is still largely catabolized via glycerol.

Assuming a catabolic pathway of D-galacturonic acid leading to GAD and pyruvate (Uitzetter et al., 1986), it is not clear why the mutant is unable to grow on Dgalacturonate, since pyruvate can still be metabolized and GAD can be reduced to glycerol, a nontoxic compound. The inability of the glycerol mutant to grow on D-galacturonate, the NMR spectra of mycelia transferred to D-galacturonate and the induction of a number of enzymes from glycerol metabolism by $D$ galacturonate confirm that D-galacturonate is catabolized, in part, via glycerol. High levels of GAD kinase are present in the mutant. With the situation for DHA in mind, it must be considered why GAD formed from Dgalacturonate is not directly phosphorylated thus allowing the mutant to grow on D-galacturonate. The situation is different from that of DHA catabolism at two points. Firstly, a strong induction of a GAD reductase takes place, stimulating a fast reduction of GAD to glycerol. Secondly, the affinity of the enzyme catalysing both DHA and GAD phosphorylation is much higher for DHA than for GAD. These two characteristics might result in phosphorylation of DHA, while GAD is preferably reduced. The position of the equilibrium far in the direction of glycerol prevents further metabolism.

Under the different growth conditions at least three different glycerol dehydrogenases are apparent, all with different functions. The highest levels of the NADPH- 
dependent enzyme that is relatively specific for DHA are found in glucose-grown mycelium. This enzyme might function in the synthesis of glycerol which accumulates in $A$. niger under certain conditions or in the detoxification of DHA formed in the cell. The repression of this enzyme by glycerol, DHA and D-galacturonate indicates that it does not per se have a role in the catabolism of these substrates. The second NADPH-dependent enzyme is induced by D-galacturonate and is involved in a step in the degradation of this substrate. Considering the relative levels of NADPH-dependent GAD reductase and DHA reductase, this particular enzyme is also very likely to be present when $A$. niger is grown on one of the other substrates. This enzyme might be comparable to the glycerol dehydrogenase isolated from $N$. crassa by Viswanath-Reddy et al. (1978). The NADH-dependent glycerol dehydrogenase, which we could measure in significant amounts only in the glycerol kinase mutant, might be involved in the oxidation of glycerol as an alternative to the phosphorylation pathway. Perhaps this enzyme has a role when the route via the membranebound mitochondrial glycerol-3-phosphate dehydrogenase is inhibited. The ability to produce at least three different glycerol dehydrogenases is similar to the situation in the yeast Schizosaccharomyces pombe, in which Kong et al. (1985) found four different glycerol dehydrogenases, with characteristics comparable to the enzymes described here.

This research was supported by the Netherlands Technology Foundation (STW), Utrecht, grant no. WBI 47.0637, and by the Agricultural University Biotechnology Program on Biocatalysts.

\section{References}

Adler, L., Blomberg, A. \& Nilsson, A. (1985). Glycerol metabolism and osmoregulation in the salt-tolerant yeast Debaryomyces hansenii. Journal of Bacteriology 162, 300-306.

Baliga, B. S., Bhatnagar, G. M. \& Jagannathan, V. (1962). Triphosphopyridine nucleotide-specific glycerol dehydrogenase from Aspergillus niger. Biochimica et Biophysica Acta 58, 384-385.

Bensadoun, A. \& Weinstein, D. (1976). Assay of proteins in the presence of interfering materials. Analytical Biochemistry 70, 241250.

BeEver, R. E. \& LaRaCy, E. P. (1986). Osmotic adjustment in the filamentous fungus Aspergillus nidulans. Journal of Bacteriology 168 , $1358-1365$

Bos, C. J. (1987). Induction and isolation of mutants in fungi at low mutagen doses. Current Genetics 12, 471-474.

Bos, C. J., Debets, A. J. M., Swart, K., Huybers, A., Kobus, G. \& SLAKHORST, S. M. (1988). Genetic analysis of Aspergillus niger and the construction of master strains for assignment of genes to linkage groups in Aspergillus niger. Current Genetics 14, 437-443.

Brown, A. D. (1976). Microbial water stress. Bacteriological Reviews 40, 803-846.

Brown, A. D. (1978). Compatible solutes and extreme water stress in eukaryotic micro-organisms. Advances in Microbial Physiology 17, $181-242$
COURTRIGHT, J. B. (1975a). Intracellular localization and properties of glycerokinase and glycerolphosphate dehydrogenase in Neurospora crassa. Archives of Biochemistry and Biophysics 167, 34-44.

Courtright, J. B. $(1975 b)$. Differential rates of synthesis of glycerokinase and glycerophosphate dehydrogenase in Neurospora crassa during induction. Archives of Biochemistry and Biophysics 167, 21-33.

DiJKema, C., Kester, H. C. M. \& Visser, J. (1985). Carbon-13 NMR studies of carbon metabolism in the hyphal fungus Aspergillus nidulans. Proceedings of the National Academy of Sciences of the United States of America 82, 14-18.

GaNCEDo, C., GANCEDO, J. M. \& Sols, A. (1968). Glycerol metabolism in yeasts. Pathways of utilization and production. European Journal of Biochemistry 5, 165-172.

Gancedo, C., Llobell, A., Ribas, J. C. \& Luchi, F. (1986). Isolation and characterization of mutants from Saccharomyces pombe defective in glycerol catabolism. European Journal of Biochemistry 159, 171-174.

Hocking, A. D. \& Norton, R. S. (1983). Natural-abundance ${ }^{13} \mathrm{C}$ nuclear magnetic resonance studies on the internal solutes of xerophilic fungi. Journal of General Microbiology 129, 2915-2925.

Holm, K., Nilheden, E. \& Kolmark, H. G. (1976). Genetic and enzymatic analysis of a glycerol kinase deficient mutant in Neurospora crassa. Molecular and General Genetics 144, 11-15.

ITZHAKI, R. F. \& GiLL, O. M. (1964). A microbiuret method for estimating proteins. Analytical Biochemistry 9, 401-410.

Kong, Y.-C., MaY, J. W. \& Marshall, J. H. (1985). Glycerol oxidation and triose reduction by pyridine nucleotide-linked enzymes in the fission yeast Schizosaccharomyces pombe. Journal of General Microbiology 131, 1571-1579.

De Koning, W., Harder, W. \& Dijkhuizen, L. (1987). Glycerol metabolism in the methylotrophic yeast Hansenula polymorpha: phosphorylation as the initial step. Archives of Microbiology 148, 314 320.

LeGiSA, M. \& MATTEY, M. (1986). Glycerol as an initiator of citric acid accumulation in Aspergillus niger. Enzyme and Microbial Technology 8, 258-259.

LIN, E. C. C. (1976). Glycerol dissimilation and its regulation in bacteria. Annual Review of Microbiology 30, 535-578.

LiN, E. C. C. (1977). Glycerol utilization and its regulation in mammals. Annual Review of Biochemistry 46, 765-795.

MAY, J. W. \& SLOAN, J. (1981). Glycerol utilization by Schizosaccharomyces pombe: dehydrogenation as the initial step. Journal of General Microbiology 123, 183-185.

MaY, J. W., Marshall, J. H. \& Sloan, J. (1982). Glycerol utilization by Schizosaccharomyces pombe: phosphorylation of dihydroxyacetone by a specific kinase as the second step. Journal of General Microbiology 128, 1763-1766.

MCGregor, W. G., Phillips, J. \& Suelter, C. H. (1974). Purification and kinetic characterization of a monovalent cation-activated glycerol dehydrogenase from Aerobacter aerogenes. Journal of Biological Chemistry 249, 3132-3139.

PAYTON, M. A. (1978). A genetic study of sugar metabolism and transport in Aspergillus nidulans. PhD thesis, University of Leicester, UK.

Pontecorvo, G., Roper, J. A., Hemmons, L. M., MaCDonald, K. D. \& Bufton, A. W. J. (1953). The genetics of Aspergillus nidulans. Advances in Genetics 5, 141-239.

RöHr, M., Kubicek, C. P., Zehentgruber, O. \& Orthofer, R. (1987). Accumulation and partial re-consumption of polyols during citric acid fermentation by Aspergillus niger. Applied Microbiology and Biotechnology 27, 235-239.

Schuurink, R., Busink, R., Hondmann, D. H. A., Witteveen, C. F. B. \& Visser, J. (1990). Purification and properties of NADP+ dependent glycerol dehydrogenase from Aspergillus nidulans and $A$. niger. Journal of General Microbiology 136, 1043-1050.

St Martin, E. J., Freedberg, W. B. \& Lin, E. C. C. (1975). Kinase replacement by a dehydrogenase for Escherichia coli glycerol utilization. Journal of Bacteriology 131, 1026-1028.

UitZeTTER, J. H. A., Bos, C. J. \& VISSER, J. (1986). Characterization of Aspergillus nidulans mutants in carbon metabolism isolated after Dgalacturonate enrichment. Journal of General Microbiology 132, $1167-1172$. 
VAN Laere, A. J. \& Hulsmans, E. (1987). Water potential, glycerol synthesis, and water content of germinating Phycomyces spores. Archives of Microbiology 147, 257-262.

Visser, J., van Rooijen, R., Dijkema, C., Swart, K. \& Sealy-Lewis, H. M. (1988). Glycerol uptake mutants of the hyphal fungus Aspergillus nidulans. Journal of General Microbiology 134, 655-659.

Viswanath-Reddy, M., Pyle, J. E. \& Howe, H. B. (1978).

Purification and properties of NADP ${ }^{+}$-linked glycerol dehydrogenase from Neurospora crassa. Journal of General Microbiology 107, 289296.
WeIBel, K. E., MoR, J. R. \& FIEChter, A. (1974). Rapid sampling of yeast cells and automated assays of adenylate, citrate, pyruvate and glucose-6-phosphate pools. Analytical Biochemistry 58, 208-216.

Witteveen, C. F. B., Busink, R., van DE Vondervoort, P., Dijkema, C., SWart, K. \& VisSer, J. (1989). L-Arabinose and D-xylose catabolism in Aspergillus niger. Journal of General Microbiology 135, 2163-2171. 